\title{
Comparative performance of isolated and fixed-base reinforced concrete structures
}

\author{
Adjou $\mathrm{N}^{1,2, *}$ and Haddadou $\mathrm{N}^{1}$
}

1 National Center of Studies and Integrated Research on Building Engineering (CNERIB), Cité Nouvelle ElMokrani, Souidania, Algiers, Algeria.

2 University of Science and Technology Houari Boumediene (USTHB), Algeria.

Corresponding Author: adjounaima@hotmail.fr

\begin{abstract}
The earthquake transmits to the structure a large quantity of energy that causes damage to structures. The seismic isolation technique can absorb a large quantity of the seismic energy. The seismic isolation concept is a new technique in earthquake engineering, its principle is quite simple, and it consists to create a discontinuity between the foundation and the superstructure, so that seismic energy cannot be completely transmitted into the structure.

Therefore, this article includes a numerical application of the nonlinear static method, the capacity spectrum method (CSM), on two types of structures, fixed base structure and isolated base structure. The CSM is one of the methods used for the evaluation of seismic performance. Its principle consists in superimposing a curve which represents the capacity of the structure originated from a non-linear static analysis (Pushover), with a curve representing the solicitation brought by the earthquake. The intersection of these two curves represents the point performance, which evaluates the maximum displacement of the structure in the plastic domain.
\end{abstract}

Key words: Damping, energy dissipation, lead rubber bearing, nonlinear static method, seismic isolation.

\section{Introduction}

The technique of seismic isolation is relatively young when compared to conventional methods of prevention against earthquakes, its appearance dates back to the early $20^{\text {th }}$ century. In Algeria, the organization of technical control of construction of Chlef (CTC-Chlef) was the first to introduce this technique through the construction of the seat of its agency in Ain Defla, located in an area of high seismicity. The project of the Great Mosque of Algiers, which is under construction, will be built by using this technique. The conventional earthquake resistant designs rely on the strength and ductility of structural elements to resist seismic induced forces and to dissipate the seismic energy, which prevents the collapse of structures in case of earthquake. On the other hand, the approach of base isolation reduces the damages due to the seismic horizontal forces transmitted to the structure (Koh and Kelly, 1985). The objective of this study was to evaluate the seismic response of two structures, a fixed base structure (conventional structure), and an isolated base structure, the method of analysis used in this study is the method of spectrum capacity (CSM). A comparison of the results obtained was made for the two structures, in terms of maximum displacement in the plastic domain (Freeman, 2004).

\section{The seismic isolation}

The principle of seismic isolation is quite simple; it consists to create a discontinuity between the foundation and the superstructure, so that seismic energy cannot be entirely transmitted into the structure. There are two categories of isolation systems extensively used. The first category includes the family of elastomeric bearings, in which the high damping rubber bearing system (HDRB), the lead rubber bearing system (LRB) and other systems can be found. The second category includes the family of sliding bearings, in which the friction pendulum system 
(FPS), and sliding bearing system without re-centering, known as seismic isolators (SI) can be found. All seismic isolation systems must meet the following three requirements (Nazé, 2006):

- Sufficient horizontal flexibility to increase the structure period and spectral demand, except for very soft soil sites;

- Sufficient energy dissipation capacity to restrict the displacements of seismic isolators;

- Adequate rigidity for the isolated structure, which must be identical to the fixed base structure under the service loads.

\subsection{Description of the studied structures}

Two structures are subject to a comparative study, a conventional structure and isolated base structure; these structures are reinforced concrete portal frames. They have a square shape, regular in plan and elevation and composed of five levels. The height of each level is $3 \mathrm{~m}$ and the plan dimensions are $(16 \mathrm{~m} \times 16 \mathrm{~m})$.

The mechanical characteristics of the materials are:

- The compressive strength of concrete at 28 days is $25 \mathrm{MPa}$.

- The modulus of elasticity of concrete is $3.2210^{5} \mathrm{kN} / \mathrm{m}^{2}$.

- Longitudinal and transverse reinforcement steel: Fe E400.

The loads $\mathrm{G}$ and the overloads $\mathrm{Q}$ are:

- Terrace: $\mathrm{G}=6.75 \mathrm{kN} / \mathrm{m}^{2}$ and $\mathrm{Q}=1.00 \mathrm{kN} / \mathrm{m}^{2}$.

- Floor: $\mathrm{G}=4.20 \mathrm{kN} / \mathrm{m}^{2}$ and $\mathrm{Q}=1.50 \mathrm{kN} / \mathrm{m}^{2}$.

The structures are considered located in an area of high seismicity (zone III) on soft ground (S3). The dimensions of structural elements are calculated in accordance with the Algerian seismic rules RPA99/Version 2003. The LRB isolation system is used in this analysis, with 25 supports (Figure 1).
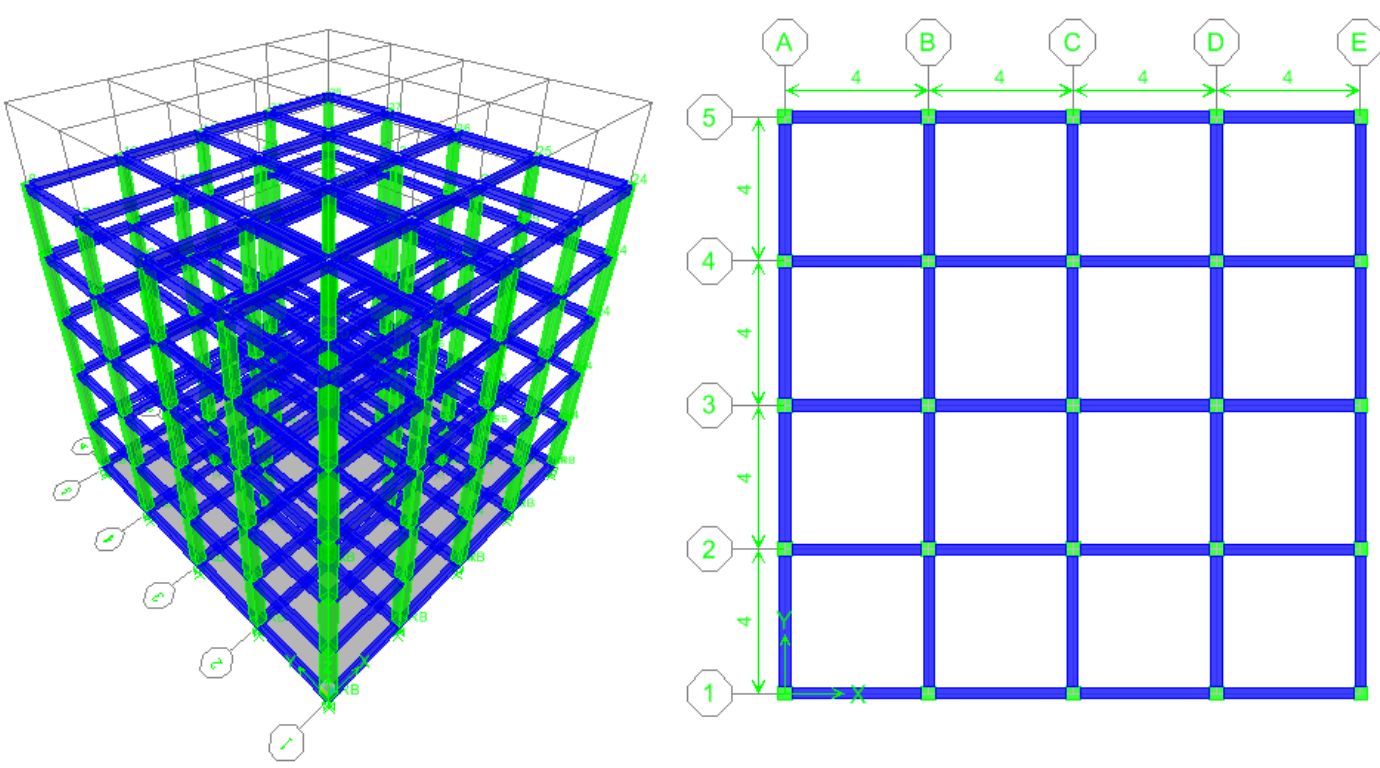

Fig 1. Graphical representation of the studied structures.

\subsection{Capacity spectrum method}

The spectrum capacity method (CSM) is an analysis approach based on the performance of structure. It was used for the first time by Freeman (2004) as a quick way to estimate the 
seismic response of buildings, thereafter it was accepted as a tool for seismic design. Its principle consists in superimposing a curve which represents the capacity of the structure outcome from a nonlinear static analysis (Pushover), with a graph of the solicitation provided by the earthquake. The intersection of these two curves represents the point of performance which evaluates the maximum displacement of the structure in the plastic range (Yang, 2003). The steps of the method are described as follows (Saez, 2006):

Step 1: Construction of the capacity curve (curve Pushover) of the structure. The Pushover analysis is a nonlinear static procedure; it is based on the hypothesis that the response of the structure may be connected to the response of an equivalent system of single degree of freedom. The formulation of the equivalent single degree of freedom system is not unique but the common basic supposition to all approaches is that the shape of the deformation of the system with several degrees of freedom can be represented as an eigenvector $\{\Phi\}$ which remains constant during all the analysis independently of the level of deformation.

Accepting this hypothesis and defining the vector of the relative displacement $\mathrm{X}$ of a system with multiple degrees of freedom, $X=\{\Phi\} X_{-} t$ ( $X_{t}$ : roof displacement), the differential equation of the system with several degrees of freedom can be written as (Krawinkler, 1996):

$\mathrm{M}\{\Phi\} \ddot{x}_{\mathrm{t}}+\mathrm{C}\{\Phi\} \dot{\mathrm{x}_{\mathrm{t}}}+\mathrm{F}=-\mathrm{M}\{\mathrm{I}\} \ddot{\mathrm{x}}_{\mathrm{g}}$

Where :

M: Mass matrix.

C: Damping matrix.

F: Force vector.

$\ddot{\mathrm{x}}_{\mathrm{g}}$ : Ground acceleration.

By defining the equivalent displacement of the system with a single degree of freedom system (SDOF), $\mathrm{x}^{*}$ :

$\mathrm{x}^{*}=\frac{\{\phi\}^{\mathrm{T}} \mathrm{M}\{\phi\}}{\{\phi\}^{\mathrm{T}} \mathrm{M}\{\mathrm{I}\}}$

By multiplying the equation (1) by $\{\phi\}^{\mathrm{T}}$, and substituting the equation (2) into the equation (1), the following differential equation of the equivalent SDOF system can be obtained:

$\mathrm{M}^{*} \ddot{\mathrm{x}}^{*}+\mathrm{C}^{*} \dot{\mathrm{x}}^{*}+\mathrm{F}^{*}=-\mathrm{M}^{*} \ddot{\mathrm{x}}_{\mathrm{g}}$

Where: $\mathrm{M}^{*}, \mathrm{C}^{*}$ and $\mathrm{F}^{*}$ are the properties of the equivalent SDOF system with a single degree of freedom.

$$
\begin{aligned}
& \mathrm{M}^{*}=\{\phi\}^{\mathrm{T}} \mathrm{M}\{\mathrm{I}\} \\
& \mathrm{F}^{*}=\{\phi\}^{\mathrm{T}} \mathrm{F} \\
& \mathrm{C}^{*}=\{\phi\}^{\mathrm{T}} \mathrm{C}\{\phi\} \frac{\{\phi\}^{\mathrm{T}} \mathrm{M}\{\mathrm{I}\}}{\{\phi\}^{\mathrm{T}} \mathrm{M}\{\phi\}}
\end{aligned}
$$

Assuming that the eigenvector $\{\phi\}$ is known, the relation force-deformation $\mathrm{F}^{*}$ - $\mathrm{x}^{*}$ of the equivalent system with a single degree of freedom can be determined from the results of nonlinear incremental analysis of the system with multiple degrees of freedom (MDOF), which results the capacity curve (base shear according to the roof displacement).

Step 2: Conversion of Pushover curve in acceleration displacement response spectral format (ADRS), capacity diagram (Chopra and Goel, 1999): 


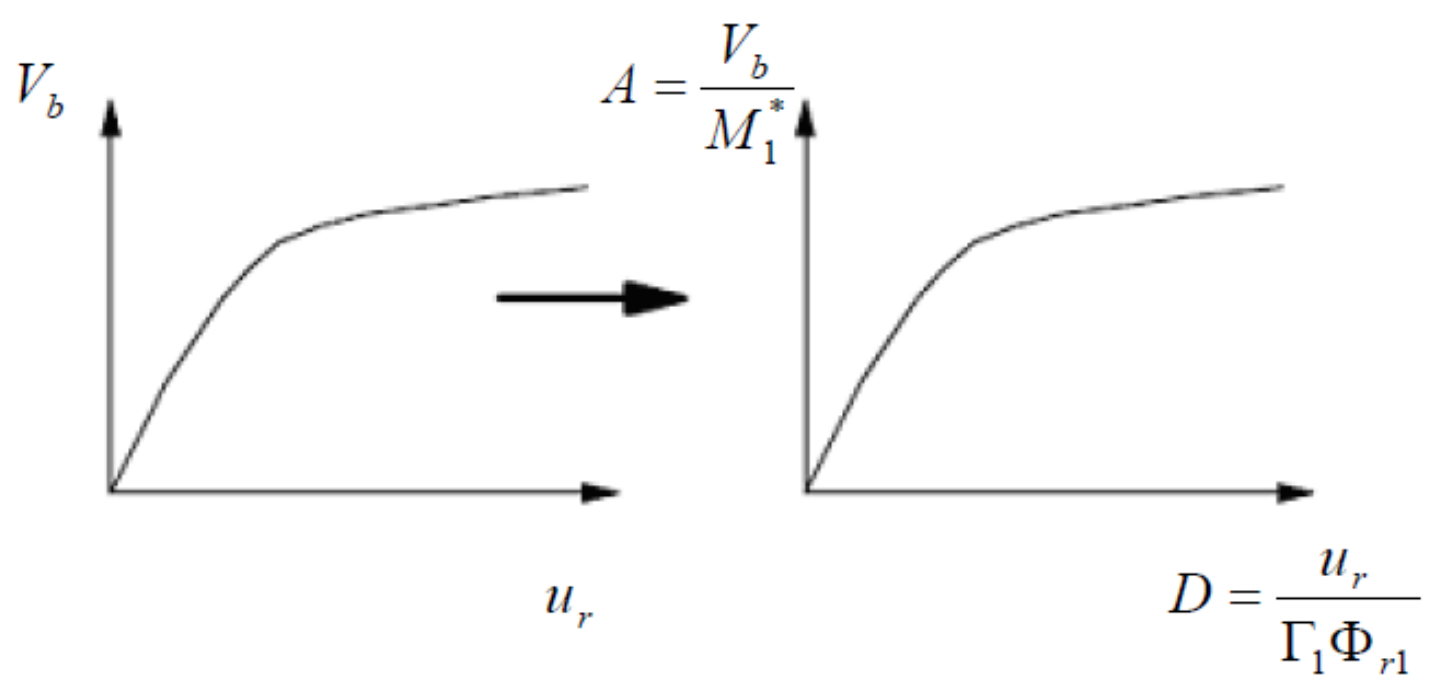

Fig 2. Conversion of the capacity curve in ADRS format.

With:

$\mathrm{D}=\frac{\mathrm{u}_{\mathrm{r}}}{\Gamma_{1} \phi_{\mathrm{r} 1}}$

$\mathrm{A}=\frac{\mathrm{V}_{\mathrm{b}}}{\mathrm{M}_{1}^{*}}$

$\Gamma_{1}=\left[\frac{\sum_{j=1}^{N} m_{j} \phi_{j 1}}{\sum_{j=1}^{N} m_{j} \phi_{j 1}^{2}}\right]$

$\mathrm{M}_{1}^{*}=\frac{\left[\sum_{\mathrm{j}=1}^{\mathrm{N}} \mathrm{m}_{\mathrm{j}} \phi_{\mathrm{j} 1}\right]^{2}}{\left[\sum_{\mathrm{j}=1}^{\mathrm{N}} \mathrm{m}_{\mathrm{j}} \phi_{\mathrm{j} 1}^{2}\right]}$

$\mathrm{M}_{1}{ }^{*}$ : Effective modal mass of the first mode

$\Gamma_{1}$ : Modal participation factor of the first mode

$\mathrm{m}_{\mathrm{j}}$ : Mass of jème level

$\phi_{\mathrm{j} 1}$ : Amplitude at level $\mathrm{j}$ of the fundamental mode

$\mathrm{N}$ : Number of levels

$\phi_{\mathrm{r} 1}$ : Amplitude of the first mode at roof level

The bilinear representation of the capacity diagram was used to calculate the ratio of ductility $(\mu)$ and the equivalent damping which includes viscous damping and hysteretic damping (Chopra and Goel, 1999). The equivalent bilinear curve is based on the criterion of equivalence of energy. For a value of maximum deformation $\mathrm{Sd}_{\mathrm{p}}$, as represented in Figure 3, the area under the capacity graph must be equal to that in the bilinear curve (deformation energy), that is, the areas $\Omega_{1}=\Omega_{2}$ in Figure 3. On the same figure, $\mathrm{Sa}_{\mathrm{y}}$ and $\mathrm{Sa}_{\mathrm{pi}}$ are the maximum acceleration and the acceleration of the yield strength; $\mathrm{Sd}_{\mathrm{y}}$ and $\mathrm{Sd}_{\mathrm{pi}}$ are the displacements corresponding to accelerations $\mathrm{Sa}_{\mathrm{y}}$ and $\mathrm{Sa}_{\mathrm{pi}}$ respectively. 


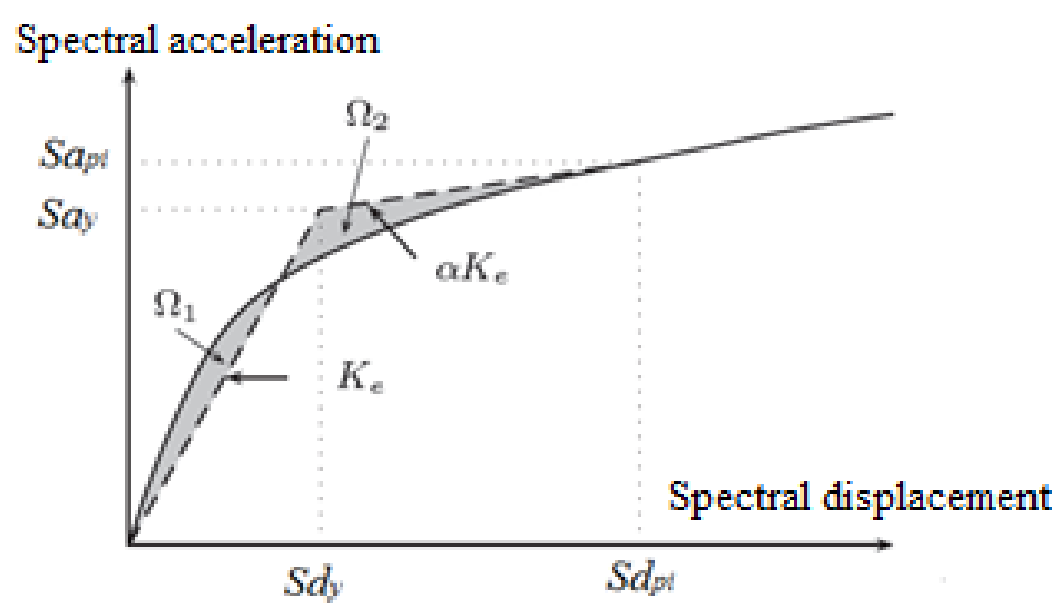

Fig 3. Equivalent bilinear model.

The rigidity of the elastic portion Ke can be expressed in terms of the elastic period:

$\mathrm{Ke}=\frac{\mathrm{Sa}_{\mathrm{y}}}{\mathrm{Sd}_{\mathrm{y}}}=\left(\frac{2 \pi}{\mathrm{T}_{\mathrm{e}}}\right)^{2}$

The maximum acceleration may be expressed in terms of the ductility $\left(\mu=\frac{S d_{p i}}{S d y}\right)$ and reducing stiffness $\alpha$ :

$\mathrm{Sa}_{\mathrm{pi}}=\mathrm{Sa}_{\mathrm{y}}+\alpha\left(\frac{2 \pi}{\mathrm{T}_{\mathrm{e}}}\right)\left(\mathrm{Sd}_{\mathrm{pi}}-\mathrm{Sd}_{\mathrm{y}}\right)=\mathrm{Sa}_{\mathrm{y}}(1-\alpha+\alpha \mu)$

By keeping the elastic period (Te) constant, the selection of different values of $\mathrm{Sd}_{\mathrm{pi}}$ gives different values of $\mathrm{Sa}_{\mathrm{y}}$ and $\alpha$. Generally, the value of $\mathrm{Sa}_{\mathrm{y}}$ doesn't vary much depending on the choice of a $\mathrm{Sa}_{\mathrm{pi}}$ by against, the value of $\alpha$ is very sensitive to the chosen value.

When the bilinear equivalence established, the system properties of an equivalent degree of freedom can be calculated.

The equivalent elastic period $\mathrm{T}_{\text {eq }}$ :

$\mathrm{T}_{\mathrm{eq}}=\mathrm{T}_{\mathrm{e}} \sqrt{\frac{\mu}{1-\alpha+\alpha \mu}}$

The equivalent viscous damping of the system is (ATC, 1996):

$\hat{\xi}_{\mathrm{eq}}=\xi_{\mathrm{e}}+\xi_{\mathrm{eq}}=\xi_{\mathrm{e}} \frac{2}{\pi} \frac{(1-\alpha)(\mu-1)}{\mu(1-\alpha+\alpha \mu)}$

Where:

$\xi_{\mathrm{e}}$ : Viscous hysteretic damping.

$\xi_{\text {eq }}$ : Viscous inherent damping.

Step 3: Conversion of the traditional spectrum to demand spectrum (ADRS format).

From a pseudo-acceleration spectrum response for a given earthquake can be constructed an equivalent representation by accelerations and displacements, as shown in Figure 4 and relation (15). 

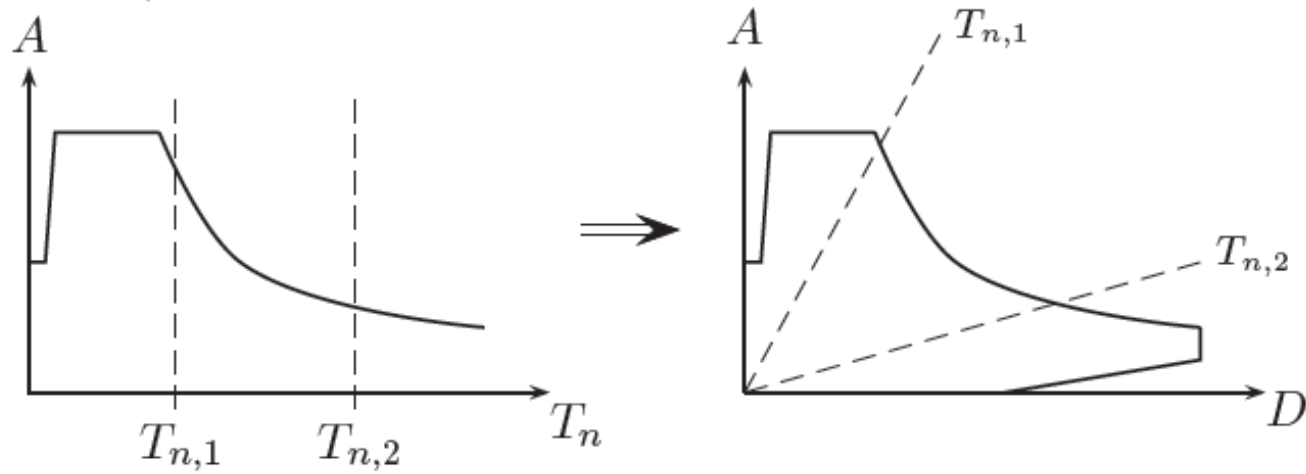

Fig 4. Conversion of the spectrum.

$\mathrm{D}=\frac{\mathrm{T}_{\mathrm{n}}^{2}}{4 \pi^{2}} \mathrm{~A}$

D: Spectral displacement.

A: Spectral acceleration.

$\mathrm{T}_{\mathrm{n}}$ : Natural period.

Step 4: Determination of the performance point of the structure. The Applied Technology Council, ATC code 40 specifies three types of methods to estimate the induced deformation. Procedures A and B are analytical (ATC, 1996). Method C is rather graphic. In general method A gives better results.

\section{Results and discussions}

\subsection{Periods and cumulated modal contribution factors}

The results obtained for the two types of structures are summarized in Table 1.

Table 1. Periods and modal contribution factors cumulated of structures.

\begin{tabular}{|c|c|c|c|c|}
\hline \multirow{2}{*}{ Levels } & \multirow{2}{*}{$\begin{array}{c}\text { Type of } \\
\text { structure }\end{array}$} & \multirow{2}{*}{ Period } & \multicolumn{2}{|c|}{ Frequency } \\
\cline { 4 - 5 } & & & & Mode Number \\
\cline { 4 - 5 } & Conventional & 0.578 & 1.730 & 5 \\
\cline { 2 - 5 } & Isolated & 1.198 & 0.835 & 2 \\
\hline
\end{tabular}

\subsection{Capacity curve}

The Pushover curves (base shear - roof displacement) are the envelopes of forces-displacements of structures and represent the overall response of the structure. The loading model selected in Pushover analysis is loading mode. The capacity curves of the two types of structures are shown in Figure 5.

\subsection{Conversion Pushover curves in ADRS format}

The capacity curves of the two structures undergo a conversion to capacity diagrams (Figure 6).

\subsection{Evaluation of the performance point}

In order to determine the performance point, the procedure A (ductility approach) is used, it involves comparing the capacity diagram of the structure (capacity to dissipate the energy and demand for energy to be dissipated) in the form of an inelastic spectrum. The inelastic spectrum is determined by reducing the elastic spectrum by factors related to the ductility and period. The response spectrum used in our work is presented in Figure 7. 

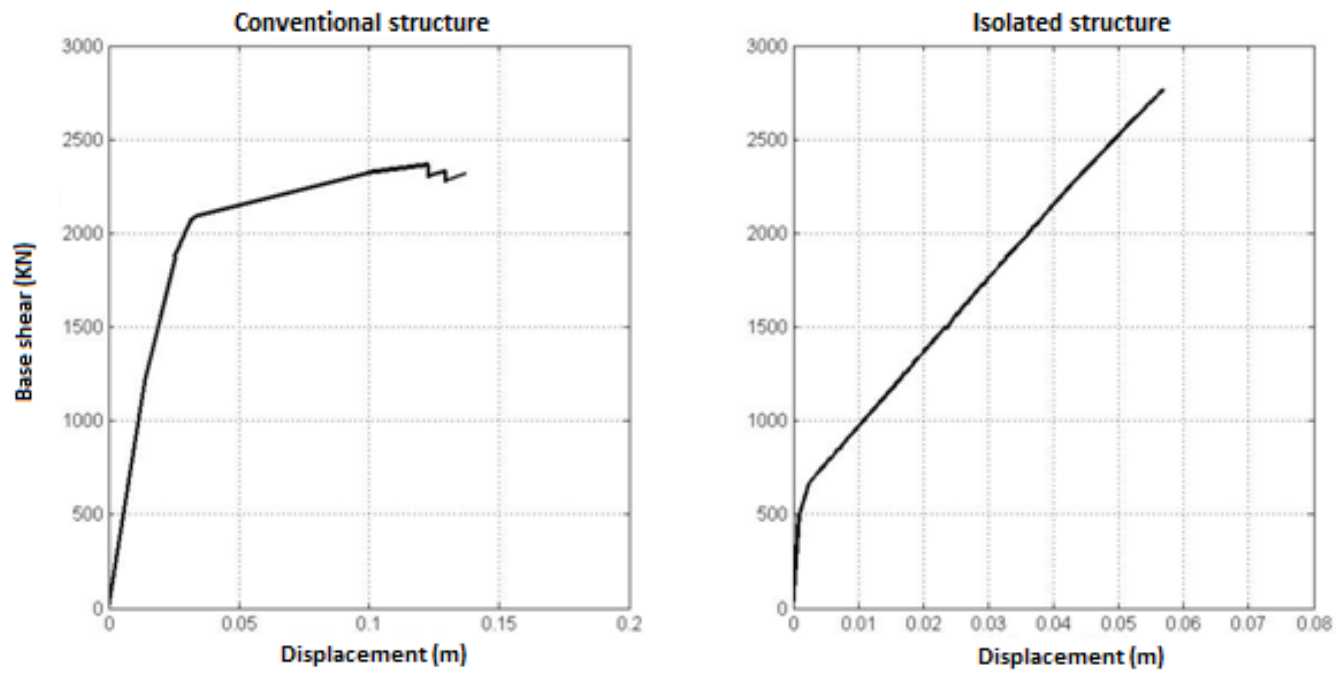

Fig 5. Pushover curves of structures.
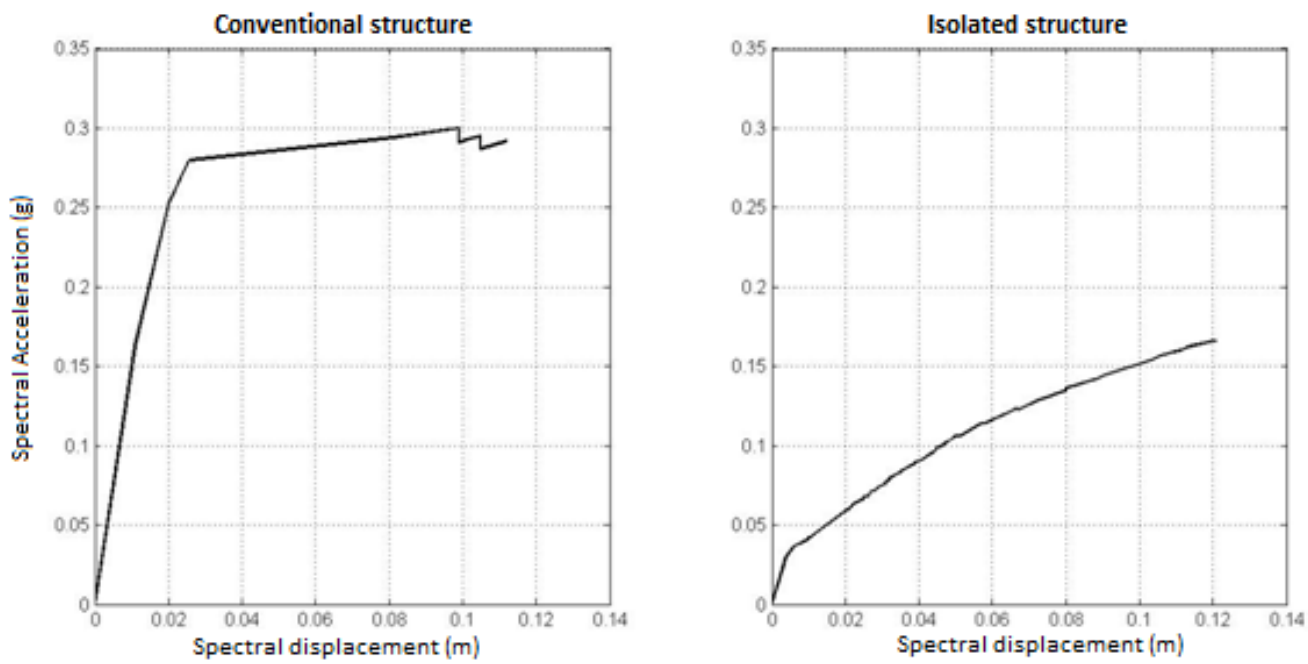

Fig 6. Capacity diagram of studied structures.

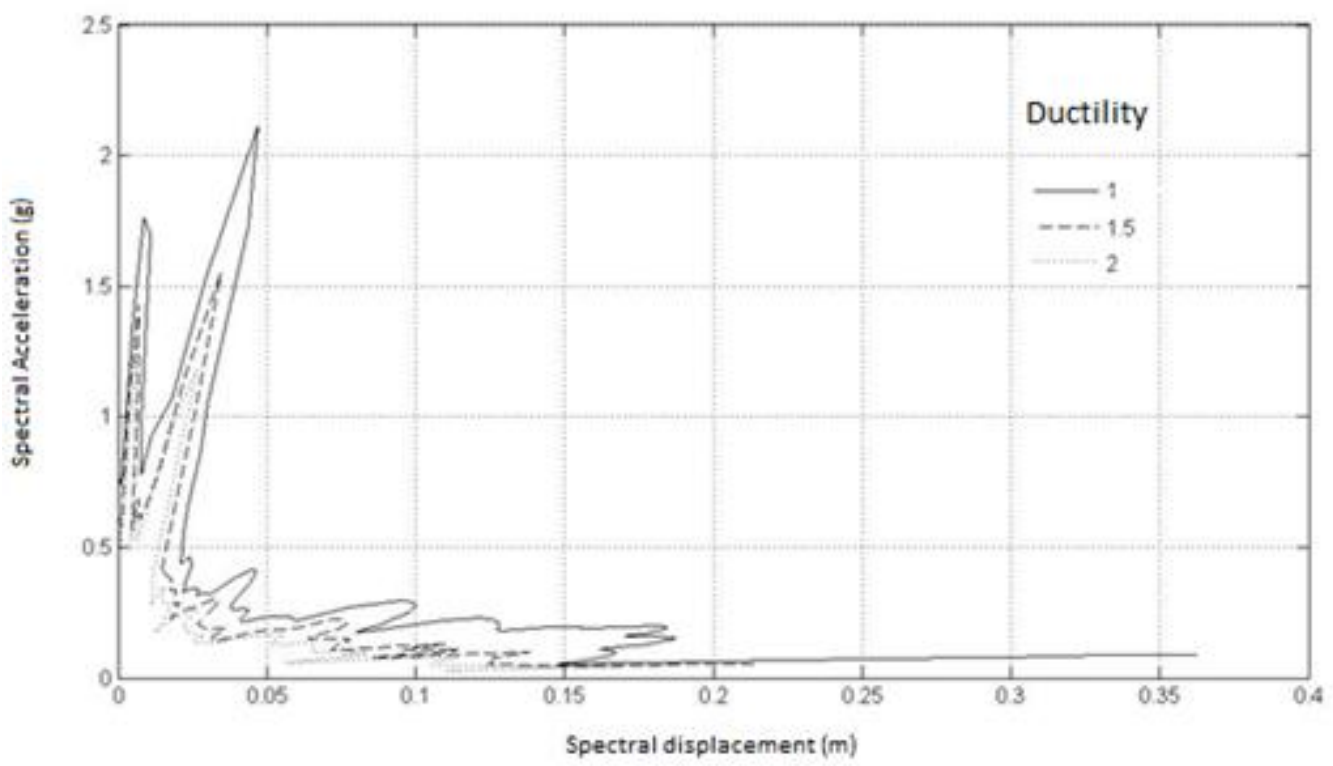

Fig 7. Inelastic response spectrum. 
The results obtained for the two types of structures are presented in Table 2 and illustrated in Figure 8.

Table 2. Result of CSM method.

\begin{tabular}{|c|c|c|c|c|c|c|c|c|c|}
\hline \multicolumn{4}{|c|}{ Conventional structure } & \multicolumn{5}{c|}{ Isolated structure } \\
\hline \hline$\mu$ & Dy $(\mathrm{cm})$ & Ay $(\mathrm{g})$ & $\mathrm{D}(\mathrm{cm})$ & $\mu$ calculated & $\mu$ & Dy $(\mathrm{cm})$ & Ay $(\mathrm{g})$ & $\mathrm{D}(\mathrm{cm})$ & $\mu$ calculated \\
\hline 1.00 & 1.75 & 0.26 & 3.90 & 2.23 & 1.00 & - & - & - & - \\
\hline 1.20 & 1.70 & 0.25 & 3.50 & 2.06 & 1.50 & 0.55 & 0.13 & 7.40 & 13.45 \\
\hline 1.30 & 1.10 & 0.27 & 2.25 & 2.05 & 2.00 & 0.55 & 0.12 & 6.50 & 11.82 \\
\hline 1.40 & 1.10 & 0.23 & 1.80 & 1.64 & 2.50 & 0.60 & 0.11 & 5.80 & 9.67 \\
\hline 1.50 & 1.10 & 0.22 & 1.65 & 1.50 & 3.00 & 0.50 & 0.11 & 5.00 & 10.00 \\
\hline- & - & - & - & - & 3.50 & 0.50 & 0.07 & 2.10 & 4.20 \\
\hline- & - & - & - & - & 3.80 & 0.50 & 0.06 & 2.05 & 4.10 \\
\hline- & - & - & - & - & 4.00 & 0.50 & 0.06 & 2.00 & 4.00 \\
\hline
\end{tabular}
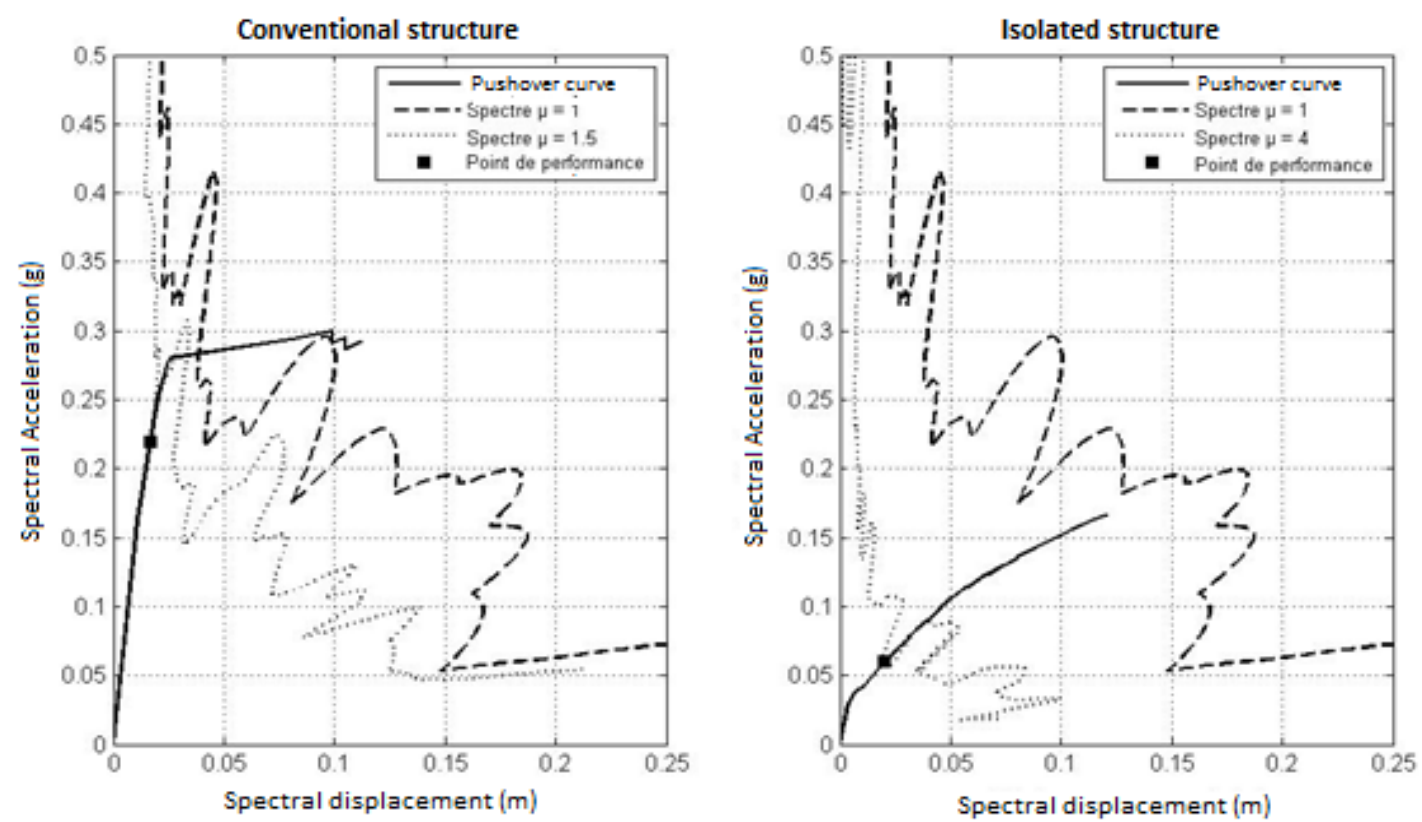

Fig 8. Performance point of studied structures.

The results recapitulated in Table 1 show that the effect of the isolation system is to relax the structure by the lengthening of the fundamental period to a greater value compared to the value obtained for the conventional structure. Indeed, the shift of the period is the primary reason for the effectiveness of the isolation system.

Figure 8 shows a comparison between the two spectrum capacity in ADRS format, the two structures have a performance point characterized by a spectral displacement, spectral acceleration and ductility (see Table 2), it must be noted that the spectral displacement in the isolated structure is greater than that of the conventional structure, and the spectral acceleration in the isolated structure is smaller than the spectral acceleration in the conventional structure. In other words, there is a reduction in the seismic demands which makes the level of the performance of structure most advantageous.

The results obtained are summarized as follows (Table 2):

- An increase in the spectral displacement of $21 \%$ which represents the displacement of the isolation system.

- A decrease in the spectral acceleration 73\% which represents the reduction of demand in terms of demands brought by the earthquake. 


\section{Conclusions}

The comparative study on the structure with and without isolation system allows highlighting the influence of seismic bearings on reducing the seismic demands, the main results are:

- The period of the isolated base structure is elongated relative to the period of the fixed base structure;

- The acceleration of the isolated base structure is smaller compared to the accelerations of the fixed base structure.

- The seismic isolation system reduces the base shear and the inter-stage displacements which cause significant damage to the structure.

The evolution over field of the use of the isolation technique, leads us to suggest the adoption of this new technology in the future Algerian earthquake resistant regulations RPA99/version2003.

\section{References}

Applied Technology Council, ATC (1996). Seismic evaluation and retrofit of concrete buildings. ATC-40, Volumes 1 and 2, Report No. SSC 96-01, Seismic Safety Commission, Redwood City, CA.

Chopra AK, Goel RK (1999). Capacity-demand-diagram methods for estimating seismic deformation of inelastic structures: SDF systems. Pacific Earthquake Engineering Center, University of California, Berkeley, Report No. PEER 1999/02.

Freeman SA (2004). Review of the development of the capacity spectrum method. ISET Journal of Earthquake Technology, 41(1), 1-13.

Koh CG, Kelly JM (1985). Fractional Derivative Representation of Seismic Response of Base-Isolated Models: Theory and Experiments. UCB/SESM 85/07, University of California at Berkeley.

Krawinkler H (1996). Pushover analysis: why, how, when, and when not to use it. In Proceedings of the 65th Annual Convention of the Structural Engineers Association of California.

Nazé PA (2004). Contribution to the prediction of structural damage in reinforced concrete under seismic loading. Doctoral dissertation, INSA Lyon, France. (In French)

Saez E (2006). Design of buildings based on the notion of performance. Doctoral dissertation, Ecole Centrale de Paris, France. (In French)

Yang YB, Chang KC, Yau JD (2003). Base Isolation. Earthquake Engineering Handbook, Chapter 17, CRC Press, Washington DC. 